\title{
Are Disagreements about Taste Possible? \\ A Discussion of Kant's Antinomy of Taste
}

\section{David Stern}

ARE DISAGREEMENTS ABOUT TASTE POSSIBLE? Nothing easier or more common, you might think. I like chocolate ice-cream, you prefer coffee. But do we really disagree? We can argue for our tastes. You might appeal to coffee's exquisite counterpoint of bitterness and sweetness; I might counter by invoking the aphrodisiac warmth of good chocolate, more bittersweet than any coffee. But defending our preferences is only likely to intensify the controversy; it is hardly realistic to expect us to definitively resolve such differences. Can there be genuine disagreement as apart from opposed preferences, when there is no possibility of rational agreement? This train of thought suggests two diametrically opposed reasons for thinking we cannot disagree about our tastes. On the one hand, if taste is purely a matter of subjective preference, then there is nothing to disagree about. On the other hand, if there is an objective matter of fact at issue, the problem is that a rational resolution seems impossible.

The dichotomy I have just sketched may appear contrived, if not ludicrous. But while the illustration is mine, the dichotomy is Kant's. It arises at the end of his discussion of aesthetic judgment in the first part of the Critique of Judgment. There, Kant denies that there is an autonomous aesthetic sense or faculty of aesthetic judgment. Instead, he argues that taste, the ability to discriminate aesthetic value, arises out of the interplay of the imagination and the understanding. Thus, taste is neither relegated nor promoted to some special corner of the mind, but involves the very capacities which make us reasoning, experiencing, and embodied beings. Taste has both a subjective aspect, in that it consists in a felt response to the aesthetic qualities of an object, and an objective aspect, in that we can give reasons for our aesthetic judgments. Kant's analysis of aesthetic judgment leads to a "dialectic," a conflict between two incompatible principles which raises the question whether the power of judgment "is lawful and hence also whether such a power is intrinsically possible" (210) and so threatens his whole project. This problem takes the form of an antinomy, a pair of incompatible theses which both seem true. 
Kant illustrates these opposed principles by appealing to what he calls two "commonplaces about taste." The first, "everyone has his own taste," is connected with the subjectivist side of our dichotomy: "the basis determining a judgment of taste is merely subjective (gratification or pain), and ... such judgments have no right to other people's necessary assent" (210). The second, "There is no disputing about taste," is connected with the opposed position, which holds that even if there is a right answer to a question of taste, one can never prove it. For it "amounts to saying that, even though the basis determining a judgment of taste may be objective, that basis still cannot be brought to determinate concepts" (210), that is, concepts that determine an object. In effect, Kant regards these commonplaces - that we disagree about taste, yet there can be no genuine disputes about taste-as givens, and then strives to find a middle way between them.

Kant articulates the differences between these positions by distinguishing two types of disagreement, "disputing" (disputieren) and "quarreling" (streiten). A "dispute" is a disagreement which we can settle rationally, by a proof based on objective concepts. A "quarrel" is a disagreement in which the participants have opposed views, but there are no objective concepts and so no method for principled resolution. This terminology is used to explain how both of Kant's "commonplaces about taste" have the same motivation. They are diametrically opposed responses to the same problem: the recognition that a dispute, the rational resolution of a disagreement over taste, is impossible. The first, subjectivist, response is to hold that differences of taste are merely differences of subjective preference, and so maintain that there is nothing which could form the basis for a quarrel, let alone a dispute. The second response is to hold that even though one can't dispute taste, differences over taste are objective differences, and so quarrels about taste are possible. As a result, the point at issue between these positions is whether one can quarrel about taste, that is, argue for one's tastes, or as Kant puts it, "lay claim to other people's necessary assent to one's judgment" (211). The first position denies that one can quarrel about taste; the second insists that one can. This is the basis for Kant's antinomy of taste, which is phrased in terms of a disagreement over whether judgments of taste are based on concepts, a precondition for reasoned disagreement. The subjectivist thesis is that "a judgment of taste is not based on concepts; for otherwise one could dispute about it (decide 
by means of proofs)" (211). The antithesis is that a "judgment of taste is based on concepts; for otherwise, regardless of the variation among such judgments, one could not even so much as quarrel about them (lay claim to other people's necessary assent to one's judgment)" (211).

Kant describes the antinomy as a difference between the empiricist view that taste is determined by experience, and the rationalist view that we can reason about a standard of taste a priori (220ff.), echoing the contrast between those who "found morality on sentiment" and those who base morality on reason drawn in Hume's essay "Of the Standard of Taste." Each side in this controversy, as is often the case where scepticism is at issue, gains much of its plausibility by playing up the implausibility of the extremes which the other side can lead to. The proponent of the antithesis can insist that there is more to judgments of taste than Humean sentiment, the empirical phenomena of approval and disapproval and their expression. The defender of the thesis can respond that the "necessary assent" which pompous people invoke when appraising aesthetic objects is worthless if it can never be backed up by proof.

To see how Kant resolves this antinomy, we must look at his account of the role of concepts in judgments of taste. In Kant's view, a judgment of taste is always based on an individual's subjective response to some specific experienced object, such as a picture or a landscape. The judgment"That's beautiful" -is an articulation of the individual's aesthetic response, which is a certain sort of feeling of pleasure. Such judgments, Kant holds, do not employ "determinate concepts." If, however, I judge that I see a painting composed of red, yellow, blue, black, grey, and white rectangles framed by a black grid, I am applying determinate concepts, for there are objective procedures for establishing the applicability of the concepts in question. In this case, the truth or falsity of the judgment in question can be objectively ascertained by any competent individual. But because we do not have such determinate concepts in the case of aesthetic judgment, we are unable to arrive at a comparable consensus. Kant then uses the notion of an "indeterminate concept" to present his view of aesthetic judgment as one which successfully mediates between two extreme positions which comprise the antinomy. He observes that judgments of taste are, in a crucial respect, very different from a simple judgment that something is agreeable. In saying that I like something, or as he puts it, that I find it agreeable, I simply express my own personal response to that thing. On 
the other hand, when I say it's beautiful, I not only express my pleasure, I also maintain that everyone else should feel the same; in Kant's words, my judgment "lay[s] claim to necessary validity for everyone" (212). This claim to necessity is a sure sign that concepts play a role in the judgment. But this is immediately counterbalanced by the claim that the concepts in question cannot be determined - and so they do not permit a proof that the object is beautiful or not. And that, in outline, is the approach Kant adopts: aesthetic judgments are conceptual, and so can claim universal validity, but the concepts are intrinsically indeterminate, and so we cannot settle aesthetic disputes.

Kant also tries to explain how this indeterminacy arises. He maintains that our aesthetic concepts depend on the "transcendental concept of the supersensible" (212), the "general basis of nature's subjective purposiveness for our power of judgment," characterizing it as a "concept [that] does not allow us to cognize and prove anything concerning the object because it is intrinsically indeterminable and inadequate for cognition" (213). This invocation of a necessarily ineffable non-entity, the indeterminable "supersensible" is supposed to solve the antinomy, by explaining how both thesis and antithesis can be true: a judgment of taste is not based on determinate concepts, (revised version of the thesis), but it is based on an indeterminate concept, namely the supersensible substrate of phenomena (revised version of the antithesis). Kant adds that no further explanation of the antinomy is possible, as the supersensible lies beyond the limits of what we can know. Any such explanation would "surpass our cognitive power.... Eliminating this conflict between the claims and counterclaims of taste is the best we can do" (213).

Let's return to the question whether disagreements about taste are possible. We can see that much depends on what you mean by "disagreement"-a dispute, a quarrel, or a brawl. Obviously brawls are possible. Obviously disputes, in Kant's sense of the term, are impossible-they would require a rational aesthetics beyond the reach of mere mortals. Kant is convinced that quarrels are possible, but that they are only possible if we believe in a noumenal (unknowable) rational aesthetics, even though we can't possibly know anything about noumena. This, I think, is a terrible position. It requires that we deny pluralism in aesthetics, and so rules out the possibility that there may be many different, equally valuable sensibilities; it requires that we place too high a value on convergence and does not 
allow us to celebrate diversity; and it backs this up by an obscurantist appeal to a ghost which though we know it can never be realized, haunts us with its demands. The supersensible is a philosophical myth which allows Kant to preserve his conviction that there is a fact of the matter about taste despite his inability to find a good argument for it: he kicks it out of the world we know only to reinstate it as a ghostly noumenal presence.

It is striking that Kant invokes the supersensible quite abruptly in his solution to the antinomy. However, in a subsequent comment he explains that this antinomy, like the parallel antinomies in the first and second Critiques, is valuable for forcing us to abandon the belief that we see things in themselves. Instead, we realize that we must treat what we see as mere phenomena arising out of something which we cannot adequately grasp, an "intelligible substrate (something supersensible, the concept of which is only an idea and precludes cognition proper)" (218). The point of this experience of moving to the very limits of intelligibility is to enable reason to recognize its own limitations, to make way for faith in something that cannot be fully understood. Here we can see a close connection with one of the central themes of Kant's philosophy: the supersensible being that Kant invokes is God. Kant's God is not known on the basis of reason; instead, reason is limited in a way that leads to faith.

A second direction in which discussion might move is beyond Kant's own concerns: we might consider how to develop Kant's ideas about "indeterminate concepts" in aesthetics quite apart from his own metaphysical system. What, in other words, is missing from Kant's account? To my mind, Kant's primary deficiency is that he rules out the role of specific communities in forming aesthetic judgment, or other forms of aesthetic diversity. But even if we are convinced that we need to take the role of community and history seriously in the variety of our responses to the objects we find and make, and thus examine the ideological dimension of even the "purest" aesthetics, we can still learn much from Kant. His emphasis on the particular aesthetic judgment, and his insistence that "there neither is, nor can be, a science of the beautiful, and a judgment of taste cannot be determined by means of principles" (230) can still provide us with a valuable point of departure. In particular, I would stress a passage in which Kant emphasizes the indispensable role of practice and communication in developing one's aesthetic sense, a capability he regards as constitutive of our very humanity: 
It seems that for all fine art, insofar as we aim at its highest degree of perfection, the propaedeutic does not consist in following precepts but in cultivating our mental powers by exposing ourself beforehand to what we call the humaniora; they are called that presumably because humanity [Humanität] means both the universal feeling of sympathy, and the ability to engage universally in very intimate communication. When these two qualities are combined, they constitute the sociability that befits our humanity [Menschheit] and distinguishes it from the limitations characteristic of animals. (231)

The humanities can still learn much from Kant's work, even though two hundred years later, we may need to develop a broader sense of "humanity" than can be found in Kant. In retrospect, Kant's antinomy cries out for both synthesis and deconstruction. It asks to be read, it asks us to explain the gap between the initial opposition and the transcendental idealist solution, both because it isn't a solution, and because he really doesn't do enough to justify, explain, or locate it. 